raised. The snake was restrained in a 1-litre measuring glass cylinder and opening around its body was covered with cotton. External examination revealed a depression at the mid-dorsum (Image $1^{\mathrm{w}}$ ). Hence a radiograph was taken to identify any spinal injury. Radiograph revealed fractured vertebrae (Image $2^{\mathrm{w}}$ ).

A two inch wide micro pore adhesive tape was applied to the body of the snake to a length of 10in including the injured segment. A $50 \mathrm{ml}$ disposable plastic syringe, cut at both the ends and slit longitudinally into two equal halves, made smooth by filing on hard surface, padded suitably with cotton and gauze, was placed as splint on the lateral aspect of the body over the micro-pore bandage previously applied (Image $3^{\mathrm{w}}$ ).

The volunteers were advised to keep the snake in a limited confinement. The snake was again presented after 20 days for removal of the bandage. After restraining the micro-pore tape was cut open (Image $4^{\mathrm{w}}$ ). On releasing the snake on the ground it exhibited slow movement. The volunteers were advised to keep it in confinement for another 15 days. The snake recovered uneventfully. The volunteers reported that they have released the snake in its natural habitat.

w See Images 1-4 in the web supplement at www.zoosprint.org

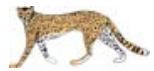

\section{VET BRIEF}

ZOOS' PRINT JOURNAL 22(6): 2736

\section{Bone plating for tibial fracture repair in a Black Buck Antelope cervicapra}

\section{R.V. Suresh Kumar ${ }^{1}$, S. Bharathi ${ }^{2}$, G. Kamalakar ${ }^{3}$, P. Veena ${ }^{4}$ and Thoiba Singh ${ }^{5}$}

1,2,4 Assistant Professors, Surgery and Radiology; ${ }^{3}$ P.G. Student, College of Veterinary Science, Tirupathi, Andhra Pradesh 517502, India

${ }^{5}$ Veterinary Assistant Surgeon, S.V. Zoological Park, Pudipatla post,

Tirupathi, Andhra Pradesh 517505, India

plus web supplement of 1 page

Fracture repair in domestic animals is a routine procedure but the same in wild animals is rare. Though fractures do occur in wild animals, lack of personnel to capture, facilities to perform surgery, complications during anaesthesia, problems in postoperative management prevent anybody to make an attempt. In this present study a case report of bone plating for tibial fracture repair in a wild Black Buck Antelope cervicapra is discussed with detailed anaesthetic and surgical procedure.

Case history: A female Black Buck aged around 12 years was presented to the college hospital with history of limping in the left hind limb. The zoo veterinarian had treated the case with analgesics and antiinflammatory drugs. Temperature, pulse and respiration were within the normal range. Palpation of mid shaft of tibia revealed crepitation and the animal was also evincing pain. No external injury was noticed. Plain radiography revealed complete fracture of tibial mid shaft (Image $\mathbf{1}^{\mathrm{w}}$ ). It was decided to perform internal stabilization under general anaesthesia.

Anaesthesia and surgical procedure: The animal was prepared for surgery; food and water withheld for 12 hours. Preoperatively, $500 \mathrm{mg}$ of metronidazole, $5 \%$ dextrose normal saline and ciprofloxacin were injected $\mathrm{i} / \mathrm{v}$. The animal was anaesthetized using combination of xylazine hydrochloride (40mg) and ketamine hydrochloride (150mg) given $\mathrm{i} / \mathrm{m}$. The animal was positioned in lateral recumbancy. The medial aspect of tibia was prepared for aseptic surgery. A $6 \mathrm{~cm}$ cutaneous incision was made and separated fascia and muscles. The proximal and distal fractured segments of the bone were identified and the site irrigated with normal saline solution to remove debris and blood clots.

w See Images $1 \& 2$ in the web supplement at www.zoosprint.org

Manuscript 1538; (C) ZOO; Date of publication 21 May 2007 Received 23 March 2006; Revised received 26 December 2006;
Using extension and counter extension the two segments were reduced to normal alignment. Eight holed Shearman's stainless steel bone plate was kept inside and $3 \mathrm{~mm}$ cortical screws were used to stabilize the bone plate to the fractured segments (Image $2^{w}$ ). Also circlage wire was applied to prevent loosening of the plate. The muscles were sutured using no. 1 chromic catgut. Sub cuticular sutures were applied to prevent dead space. Cutaneous incision was closed using no.1 braided silk. Tincture benzoin seal was applied to the suture line. Plaster of paris cast was applied to the limb for external immobilization leaving an adequate window for dressing of surgical wound. The animal received metronidazole (500mg), ciprofloxacin (500mg), $5 \%$ dextrose normal saline $(1000 \mathrm{ml}) \mathrm{i} / \mathrm{v}$ for five post operative days along with dressing of wound.

Xylazine and ketamine provided satisfactory anaesthesia for the entire surgical procedure without any complications (Lumb \& Jones, 1996). Similar anaesthetic protocols were also reported by Jalynski (2003) for treating fractures in sheep. Bone plating with cortical screws provided effective stabilization of fractured segments. External immobilization with plaster of paris cast prevented movement of segments and allowed regular dressing of the surgical wound. Pre-, intra- and postoperative use of antibiotics and fluids provided aseptic conditions of site without any problems.

\section{References}

Jalynski, M. (2003). The use of an external fixator MACZEK to treat fractures in sheep. Indian Veterinary Journal 80: 642-646.

Lumb, W.V. \& E.W. Jones (1996). Anesthesia of wild and laboratory animals, pp.698-701. In: Veterinary Anesthesia. $3^{\text {rd }}$ edition. Williams and Williams Mary land USA.

Acknowledgement: Authors acknowledge the necessary permission from the Associated Dean, Dr. V. Haragopal, Professor of Surgery College of Veterinary Science; A. Partha Sarathy, In-charge Curator, S.V. Zoo Park; sergeant and the animal attendants for their help during this work.

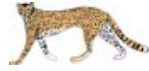

\section{VET BRIEF}

ZOOS' PRINT JOURNAL 22(6): 2736-2737

\section{Occurrence of Babesia infection in Leopard Panthera pardus at Nagpur}

\section{B.S. Baviskar ${ }^{1}$, P.J. Gawande ${ }^{2}$, D.K. Maske ${ }^{3}$, A.K. Jayraw ${ }^{4}$,} S.S. Bawaskar ${ }^{5}$ and A.G. Bhandarkar ${ }^{6}$

1,2,3,4,6 Department of Parasitology, Nagpur Veterinary College, M.A.F.S.U., Seminary Hills, Nagpur, Maharashtra 440006, India

${ }^{5}$ Maharajbagh Zoo, College of Agriculture, Nagpur, Maharashtra, India Email: ${ }^{1}$ drbaharbaviskar@rediffmail.com; ${ }^{2}$ drpriyagawande@gmail.com; 4 jayrawanant1@rediffmail.com

plus web supplement of 1 page

Babesiosis is a tick-borne haemoprotozoan disease caused by Babesia sp. and characterized by pyrexia, haemolytic anaemia, haemoglobinuria, jaundice and death. In India, babesiosis is widespread and recognized as one of the serious problem of major economic significance in domestic animals, although, sufficient information is not available on incidence of the disease in wild animals (Arora, 1994). Hence, these cases of babesiosis in Leopard Panthera pardus from Maharajbagh Zoo, Nagpur, Maharashtra are reported here.

Two 15-year old male leopards died at Maharajbagh Zoo, College of Agriculture, Nagpur with a history of anorexia, dehydration, convulsions and lumbar pain. Postmortem examination was performed; heart blood smears were prepared, stained with Leishman's stain and

w See Image 1 in the web supplement at www.zoosprint.org

Manuscript 1696; (C) ZOO; Date of publication 21 May 2007 Received 22 December 2006; Revised received 18 April 2007; Finally accepted 27 April 2007 
examined. Peripheral blood smears from another 16 -year old ailing female leopard having a history of complete anorexia and severe dehydration, were similarly stained and examined for haemoprotozoan infection.

Blood smear examination revealed Babesia sp. organisms from both the dead as well as ailing leopards (Image $1^{\mathrm{w}}$ ), which is in consonance with the findings of Upadhye \& Dhoot (2000) who recorded babesiosis from the same zoo. Similarly, Shortt (1940) also reported Babesia sp. organisms in a leopard from Coimbatore district. Khurana (1969) and Sinha et al. (2000) observed babesiosis in a white tiger from National Zoological Park, Delhi and in a tigress form Birsa Jaivic Udyan, Ranchi, respectively. The complete anorexia recorded in ailing leopard conforms to the findings of Khurana (1969), Upadhye \& Dhoot (2000), and Sinha et al. (2000), who recorded anorexia in white tiger, leopard and tigress, respectively. Additionally, all the dead leopards manifested clinical symptoms, viz., dehydration, convulsions and lumbar pain, before death. The PM examination revealed oedematous lungs, splenomegaly, congestion of liver and kidney and pale mucous membranes indicating severe anaemia, which is in conformity with the findings of Upadhye \& Dhoot (2000), who also illustrated enlargement of the spleen.

\section{References}

Arora, B.M. (1994). 100-103pp. Wildlife Diseases in India. $1^{\text {st }}$ edition. Associated Offset Press, Delhi.

Khurana, D.D. (1969). Babesiosis in a white tiger - A case report. Orissa Veterinary Journal 4: 52-53.

Sinha, K.P., M. Sinha, N.K. Pankaj \& V.K. Singh (2000). Babesiosis in a tigress. Zoos' Print Journal 15(8): 327.

Shortt, H.E. (1940). Babesia spp. in the Indian leopard Panthera pardus fusca, Meyer. Indian Journal of Medical Research 28: 277-278.

Upadhye, S.V. \& V.M. Dhoot (2000). Sudden death of a leopard (Panthera pardus) due to babesiosis. Zoos' Print Journal 15(8): 327.

Acknowledgement: The authors are thankful to the Associate Dean, Nagpur Veterinary College, M.A.F.S.U., Nagpur for providing necessary facilities.

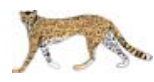

VET BRIEF

ZOOS' PRINT JOURNAL 22(6): 2737

\section{A note on occurrence of Spirometra infection in Leopard Panthera pardus from Nagpur region}

\section{P.J. Gawande ${ }^{1}$, B.S. Baviskar ${ }^{2}$, D.K. Maske ${ }^{3}$,} A.K. Jayraw ${ }^{4}$ and S.W. Kolte ${ }^{5}$

1,2,3,4,5 Department of Parasitology, Nagpur Veterinary College, Maharashtra Animal and Fishery Sciences University, Seminary Hills, Nagpur, Maharashtra 440006, India

Email: ${ }^{1}$ drpriyagawande@gmail.com; ²drbaharbaviskar@rediffmail.com; 3,4 jayrawanant1@rediffmail.com ( ${ }^{3}$ corresponding author)

Spirometra species are rarely pathogenic but the plerocercoids are of public health significance as a cause of sparganosis in human beings. In India, Spirometra infection has been reported from wild carnivores like Lion, Tiger, Wolf, Leopard, Jackal, Jungle Cat, Fox and Indian lesser cat (Niphadkar et al., 1989; Rao \& Acharjyo, 1994; Thiruthalinathan et al., 1998; Jithendran, 2002). This note is of Spirometra infection in Leopard from Nagpur region is reported here.

An ailing 4-year old leopard (Panthera pardus) of the Forest Department, Tah-Wadsa, Chandrapur district, Maharashtra was presented for treatment at Nagpur Veterinary College Hospital, Nagpur. The animal later succumbed to severe injuries. At necropsy, the intestine was filled with parasites; the intestinal contents were collected and examined qualitatively for parasitic infections. Helminth parasites were collected, washed and stained for taxonomic identification (Yamaguti, 1959)

Macroscopic and microscopic examination of the collected parasites revealed the pseudophyllidian cestode (without a well defined scolex but acetabulum with a pair of grooves). Further, ova isolated by trichurating the gravid segments indicated operculated eggs, which were pointed at each end, confirming the Spirometra infection.

\section{References}

Jithendran, K.P. (2002). A note on helminth infections of captive wild felids in Himachal Pradesh. Journal of Veterinary Parasitology 16(2): 189190.

Niphadkar, S.M., V.S. Narsapur, V.S. Deshpande \& R.S. Nehete (1989). Parasitic infections of zoo animals in Bombay. Journal of Bombay Veterinary College 1: 37-40.

Rao, A.T. \& L.N. Acharjyo (1994). Etiopathology of mortality in Indian lesser cats at Nandankanan Biological Park. Indian Veterinay Journal $71(6)$ : 550-553.

Thiruthalinathan, R., B.R. Latha \& D. Swaminathan (1998). Incidence and treatment of Spirometra infections in wild carnivores under captivity. Cheiron 27(1-2): 33-34.

Yamaguti, S. (1959). Systema Helminthium. Inter Science, New York, NY, pp.338-361.

Acknowledgement: The authors are thankful to the Associate Dean, Nagpur Veterinary College, Maharashtra Animal and Fishery Sciences University, Nagpur for providing necessary facilities.

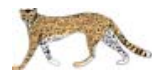

VET BRIEF

ZOOS' PRINT JOURNAL 22(6): 2737-2738

\section{Rehabilitation of an injured Shikra Accipter badius}

I. Nath ${ }^{1}$, J.K. Das ${ }^{2}$, S.K. Panda ${ }^{3}$, S.S. Lenka ${ }^{4}$ and K.L. Purohit ${ }^{5}$

${ }^{1}$ Associate Professor, ${ }^{2}$ Assistant Professor, Department of Surgery

${ }^{3}$ Assistant Professor, Department of Pathology, ${ }^{4}$ U.G. Scholar, Orissa

Veterinary College,Bhubaneswar, Orissa 751003, India

${ }^{5}$ Range Officer, O/O Chief Wildlife Warden, Bhubaneswar, Orissa, India

Email: ${ }^{1}$ indravet@yahoo.co.in

plus web supplement of 2 pages

Urbanization and the consequent loss of natural habitat has led to an increasing number of confrontations between wildlife and man. There is also an increased public awareness to help the injured wild animals. Because of their beauty and biology birds of prey enjoy a status of high priority (Hatt et. al., 1995).

The forest range officer of Bhubaneswar presented an injured bird of prey to the surgery clinic of Orissa Veterinary College - the bird was unable to fly and was chased by stray dogs in the outskirts of Bhubaneswar. The Shikra was restrained physically with securely holding its head at its back and the legs. On physical examination a compound fracture of its left wing was detected (Image $1^{\mathrm{w}}$ ). A radiograph of the affected wing revealed a distal radio-ulnar fracture with a bullet embedded in it (Image $\left.2^{\mathrm{w}}\right)$. The bullet was palpated through the skin and a nick incision was given (Image $3^{\mathrm{w}}$ ) to take out the bullet (Image $4^{\mathrm{w}}$ ). The wound was irrigated with povidon-iodine lotion and one retention was applied to appose the skin edges leaving a drainage point. The retrieved bullet was suspected to be fired from an air gun rifle. The wing was immobilized with a splint made of micro-pore adhesive tape which was additionally supported with pieces of broom stick kept under the tape. The Shikra was handed over to a care taker for routine care. The bird was kept in a paper carton with small holes for ventilation. Small pieces of chicken

${ }^{w}$ See Images in the web supplement at www.zoosprint.org

Manuscript 1692; (C) ZOO; Date of publication 21 May 2007 Received 18 December 2006; Revised received 25 March 2007; Finally accepted 27 April 200 